\title{
nama \\ Older People, Mobile Communication and Risks
}

\author{
Loredana Ivan $^{1, *}$ and Mireia Fernández-Ardèvol ${ }^{2}$ \\ 1 Communication Department, National University of Political Studies and Public Administration (SNSPA), \\ Bucharest 012104, Romania \\ 2 Interdisciplinary Internet Institute (IN3); Open University of Catalonia, Barcelona 08018, Spain; \\ mfernandezar@uoc.edu \\ * Correspondence: loredana.ivan@comunicare.ro; Tel.: +40-723-276-080
}

Academic Editor: Stephen Katz

Received: 27 February 2017; Accepted: 12 April 2017; Published: 14 April 2017

\begin{abstract}
Starting from Beck's concept of reflexivity, the paper investigates differences in risk perception regarding wireless technologies expressed by older people living in Romania and Catalonia (Spain). We combine evidence from conversations held with older individuals in different research projects together with an ad-hoc media content analysis. Our research reveals that seniors' discourses were consistent with the media prominence of different types of risks in each country. Results show that seniors' discourses on health risks relate to the way the media discussed them, with Romanian participants, in contrast to older people from Catalonia, expressing no concerns about electromagnetic radiation. Also, Romanian seniors were more concerned about the risk to others-younger family members-whereas seniors in Catalonia were more concerned about their own risks. Seniors from Romania made more references to the country's development. We discuss aging futures in societies with different risk perceptions. As the media presents the risks associated with digital technologies in differing lights, people's perceptions are formed accordingly. Also, in countries where technology is perceived as good per se, the techno-optimistic discourse would be reinforced not only by the media but also by the groups exposed to the highest social pressure towards technology adoption-for example, seniors.
\end{abstract}

Keywords: risk perception; older people; technology risks; wireless technologies risks; mobile communication risks

\section{Introduction}

Visions of aging futures include an intensive use of wireless technologies. As for the public discourses fostered by the European Union, (future) good "old age" should include smart homes that facilitate aging in place. Thus, the Internet of Things (IoT) becomes the necessary infrastructure and society will rely on permanent connectivity in search of an enhanced quality of life-among others, see [1,2]. Mobile telephony is the current basic technology that enables the IoT and, therefore, approaches to aging digital futures should include this particular technology. However, it does not come alone, as the pervasiveness of wireless communications constitutes one of the new kinds of risks that define modern risk societies [3,4] and undermine existing risk systems and risk calculations [5]. Even though it qualifies as a "new" technology that only became popular in the 1990s, mobile telephony ranked seventh among the ten most controversial technologies in the period 1977-2008 [6].

Risks are all around [7]: they come with new technologies, such as genetically modified crops, and old technologies, such as ladders; they are present in modern medicine and traditional home remedies. Risks can have immediate or delayed, direct or indirect effects. They can be voluntary or involuntary and can involve a one-time event or repeated events. Among them, mobile telephony is one of the high-modernity, human-made risks [4]. Individuals may choose to use mobile handsets or 
not, but menus of choice are limited and institutionally constrained [8] and, as long as societies rely on this particular infrastructure, individuals have to face the challenges that come with mobile telephony.

\section{Risk Perception and Age}

In general, older people tend to be more aware/concerned about risks than younger generations [9]. The younger age segment (15-24 years old) expresses lower levels of concern regarding risks related to mobile telephony [10]. Older people are also supposed to face higher levels of neophobia [11]—that is, higher unwillingness to try new things-and are usually described as more skeptic users of mobile telephony [12] compared to younger generations. This could shape older people's concerns about mobile phone overuse, with fraud or scams on the phone, or about possible adverse health effects. While Internet and mobile phones with Internet access are increasingly popular among older people [13], studies describe older people, in general, as approaching mobile communication in a utilitarian way, e.g., [14]. Therefore, the mobile phone can also be perceived as a risk management tool, valuable in terms of safety and security issues, which appears to motivate initial adoption among older individuals.

In summary, in the current context, neophobia is generally greater for older people and tends to correlate with higher degrees of concern about digital technologies. Therefore, it is of great interest to "determine whether neophobia inherently increases with age, or whether it will gradually disappear as the younger people, who are at present more positive toward new technology, become the older consumers of tomorrow" [11] (p. 69).

New questions with regard to our aging futures arise: will future societies show higher or lower levels of precaution behavior due to the demographic shift towards aging? Should we expect more conservative public policies regarding risk management when societies age? The aim of this paper is to contribute to furthering this discussion by looking at the perception of risk related to mobile communication among older people in two different European contexts, Romania and Catalonia (Spain). As risk perceptions tend to be different in developing and developed countries, we believe that the selection of the two countries could serve to envisage such differences in the case of mobile telephony.

As long as risk constitutes a defining element of contemporary societies, including the risk dimension as part of a reflection on aging futures is relevant. In this sense, starting from Beck's concept of reflexivity [3], we will examine both the discourses of older people and media discourses around different risks associated with mobile telephony in Romania and Catalonia. Our aim is not to evaluate whether participants in our research project have correct or incorrect information about the risks associated with mobile communication. Instead, we discuss the controversies reflected in the media and whether these debates are reflected in older individuals' discourses.

\section{Analytical Framework and Research Questions}

\subsection{Risks Associated with Mobile Telephony}

While techno-optimistic discourses are common, mobile technology is not free of concerns. The effects of radiation emitted by handsets and antennas on health are not clear $[15,16]$, while other associated risks, such as fraud, spam, sexting, cyber-bullying or game addiction, also arise [17]. However, the personal and social advantages of using mobile telephony can undermine/moderate the sense of risk $[18,19]$, and populations can come to regard base stations as symbols of economic and technological development.

Some of the risks associated with mobile telephony are ambivalent and linked to uncertainty. Risk is different from uncertainty because risk involves knowledge of both likelihood and consequences, whereas uncertainty refers to situations in which an accurate evaluation of the outcomes is not possible [18]. Broadly speaking, risk includes a certain uncertainty; and if there is no uncertainty, "if causality is spatially and temporally unified with a condition, action and effect" [20] (p. 166), there is no risk [20]. Still, as Beck [3] argues, especially with regard to technology, we face a chronic uncertainty 
that questions our openness to innovation. In this sense, risk differs from uncertainty in that we depart from rational calculation to subjective evaluations. Uncertainty is a form of indeterminate risk, which has a predictive control, spreading beyond the limits of expert knowledge. We can talk about uncertainty as a less definable and predictable form of risk and as the subject of chaos and complexity. The proliferation of risks must have an appeal to an audience and, through mass media, has the potential to intervene in individuals' everyday life by creating uncertainty with regard to the future.

Uncertainty is mostly linked to the long-term health risk associated with mobile telephony due to electromagnetic frequency radiations [21]. Health risks related to mobile telephony tend to be perceived as less serious than a range of other risks [18]. It is an everyday life device, usually identified with home appliances, that individuals decide when and when not to use, seeing it as less risky than other infrastructures, such as antennas [22]. In this sense, Barnett and Timotijevic gathered qualitative evidence indicating that "[mobile] phones were seen to be an indispensable part of modern life-even to those that were concerned about possible health risks" [18]. The authors argued that the benefits of mobile phone use were considerably more salient than any possible adverse health effects associated with phones and masts.

Moreover, evaluations of risk depend on whether the individual perceives "who will be harmed" [18] (p. 94). The literature distinguishes between personal risk, that is, the risk that pertains to oneself, and general risk, the risk that pertains to other people [23,24]. Interestingly, personal risk tends to be judged as inferior to the general risk in the case of lifestyle risks, such as with alcohol [24]. A particular case of general risk is risk for family, which, due to the closeness of the involved individuals, will have particular estimations of risk, with expected higher degrees of worry [25]. In the particular case of mobile communication risks, there appears to be a consensus that children, older people and those in poor health may be particularly vulnerable [18].

\subsection{The Role of the Media}

Risk is a capacious term that, to a certain extent, is conditioned by context [26], so standards of risk acceptability may vary across cultures $[27,28]$. Also, risk perception shapes the way societies manage risks, as a phenomenon "without human attention [...] is not a risk in the modern sense of the word. [...] Attention and judgment create a risk in this sense; modern systems of risk assessment that classify, select and respond bring attention to bear on a danger and give the newly formed risk meaning and technical precision" [29] (p. 4).

The media helps raise public concerns [30,31], and open discussions about the potentially adverse effects of radiofrequency electromagnetic fields from mobile telephony are common in Europe-e.g., [15,32,33]. Particularly, the media became "key actors in informing the public about scientific developments concerning potential health risks from mobile telecommunication" [34] (p. 145). Moreover, even though their core objective is not the dissemination of knowledge about risk, the media constitutes "a massively important organ for doing so" [27] (p. 145). The media constitutes the main source of information about risk and uncertainty for lay people [18] and, therefore, shapes the (accurate and inaccurate) beliefs, or mental models [35,36], about any hazard.

Audiences face information about precautionary actions and uncertainty. Although the discourse of precautionary actions in using mobile phones can reduce concerns, imperatives to precaution might cause people to worry more [37] or, at least, create misunderstandings [38]. Taking into account that people are willing to reduce uncertainty and regain trust, these studies point out that - when individuals are exposed to unspecific answers regarding mobile telephony's health effects-two main scenarios can appear. On the one hand, individuals would look for more information to make better, more informed decisions. On the other, public controversy would induce moral panic, i.e., misconceptions about technology use, risk management and control [16]. Experimental studies conducted on the influence of precautionary advice about mobile phones (for a review, see [37]) found that in precaution conditions, individuals reported higher perceived risks of mobile telephony and decreased trust in public policies. Also, participants who were more negative in evaluating uncertainty 
and those who received poor information became more concerned when they got precautionary advice. Thus, recommendations regarding taking precautions when using mobile phones to prevent different risks could be interpreted differently depending on the perceived trustworthiness of the sources [39]. Yet, there is no specific evidence regarding older people in this area.

\subsection{Understanding the Two Cultural Contexts: Romania and Catalonia, Spain}

The last published opinion poll on risk perception associated with mobile communication technologies at EU level shows that Romania's population tends to be less concerned than Spain's. Romania usually ranks below the European Union average, while Spain tends to stay above it [10]. These data were reported in 2010 and there are no new opinion polls on the subject, indicating a reduction in public attention on the matter, despite the sustained interest of the European authorities-e.g., [21].

Beyond opinion polls, research has kept its interest focused on risk perception related to wireless technologies in the European Union. This research, however, tends to focus on the middle age population—e.g., [40]—or establishes upper boundaries that exclude most parts of the older population, for instance, when surveys only include the population up to age 69 (for Germany) [41] or 70 (for Romania) [42]. In any case, available evidence reproduces the general pattern of uneven distribution of concerns related to mobile phones among countries [32]. In Spain, and particularly in Catalonia, the opposition to the installation of base stations for cell phone communications shaped infrastructure deployment-e.g., [43]. This is not the case in Romania, where a survey showed that this risk is not seen as a major concern, a result that might be related to the lack of information that surveyed individuals reported (for Romania) [42]. Regarding older people, we have already identified particularities in the way they perceived the risks associated with mobile communication in these two contexts [44].

Differences between Romania and Catalonia might also exist because risk perceptions tend to be different in developing and developed contexts. In developing countries, such as Romania, there is hardly any public debate about potential risks caused by base stations (antennas). Particularly, a study in Bangladesh [19] shows, on the one hand, that mobile base stations are associated with modernity, and, on the other hand, that those health risks are not perceived to be as important as crime but instead as more of a social inconvenience related to the use of mobile telephony. In contrast, in developed countries, the attributes associated with technology are often more related to catastrophes and potential dangers and tend not to take the benefits of technological products for granted [45]. This seems to be the case of Catalonia.

\subsection{Research Questions}

Starting from Beck's concept of reflexivity [3], which includes the assumption that attention and evaluation create awareness about risk(s), we research older people's risks perception regarding mobile communication in two social contexts: Romania and Catalonia (Spain).

First, we take into account the differences in each country to analyze individuals' risk perceptions. RQ1: Are there differences in risk perception expressed by older individuals living in contexts where the information the media provide on the issue is different? What are these differences and how do they reflect media discourses?

Also, the literature on risk perceptions distinguishes between the evaluation of risks from oneself and for others, and also between risks that are under our control and risks we do not control. Following such distinctions, we formulate the second research question.

RQ2: Are there differences regarding older individuals' concerns regarding "their own risk" and "third party risks" in the case of mobile communication in Romania and Catalonia, Spain?

\section{Methodology}

This paper combines evidence from conversations we had with older individuals in different research projects carried out since 2010 with an ad-hoc media content analysis. We explain the methods 
in chronological order, distinguishing between the research's initial stage (2010-2012) and the follow-up period (2013-2016).

Initial research. The first set of interviews included 23 participants in Romania (Bucharest, selected cities, and selected rural towns) and 47 in the Barcelona metropolitan area, and was conducted between October 2010 and August 2012 [44]. We used a flexible, interactive research design for both to take into account the specific circumstances in which the research was conducted [46]. Semi-structured interviews served for data gathering. Conversations followed an open, flexible outline and focused on the communication channels used, with a particular interest in mobile phones and, by extension, the Internet. The interview included questions about the advantages and disadvantages of mobile telephony, and participants brought up issues regarding the risks of using communication technologies.

In light of these results, we conducted a complementary content analysis to investigate the presence of different types of risks with regard to mobile telephony in the mainstream media, both in Romania and Catalonia. Media source selection followed criteria of similarity regarding audience and accessibility of content. We selected culturally relevant media in each context, so we can consider they relate to the opinions of participants. We combined traditional and new media to capture the greatest variety of discourses, with one digital media outlet and one traditional journal in each context. For Romania, we used one of the two largest news portals, Hotnews (www.hotnews.ro), and the journal with the largest audience, which largely covers the area of Bucharest, Adevarul [47]. For Catalonia, we used the news portal 3-24 (www.324.cat) and the leading newspaper La Vanguardia [48]. The two newspapers have fully accessible online libraries (www.adevarul.ro and www.lavanguardia.esrespectively). The analysis timeframe spanned three years (2010-2012), and the final corpus of study contains 368 items: 224 news items in the Romanian media and 144 in the Catalan media. The selected timeframe responds to two criteria: firstly, the most systematic and comparable primary qualitative evidence corresponded to the period 2010-2012; secondly, information on the issue in the Romanian media before 2010 was scarce.

Validity and reliability. In the inquiry process, we used verification strategies to assure methodological congruence of the research in the two social contexts. Interviews were conducted following the same research protocol in the two countries and saturation rate was considered. Participants were selected when balancing for gender, age category and education. Also, when conducting content analysis, we employed the same criteria for selecting media sources, corpus, keywords searched and categories coded. The final category list was refined following the principle of appropriateness and completeness [49].

Follow-up. Afterward, different digital media research projects gave us the opportunity to stay focused on the evolution of the risk perception related to mobile communication and mobile technologies among older individuals.

The corpus of analysis comes from qualitative evidence gathered in four research projects conducted between 2013 and 2016. In Romania, a project analyzing family communications interviewed eight grandmothers who used Facebook [50]. Collaborative research was also carried out on the use of technology later in life in three different regions of the country based on three focus group discussions and 32 personal interviews [51]. In Catalonia, an analysis of the smartphone use included three focus group discussions with older individuals [52]. Finally, a one-year project exploring the appropriation of smartwatches established periodic interviews and two focus group discussions with five older individuals [53].

The risk question. During the initial research phase, interviews did not trigger participants to express their concerns about the use of mobile communication in the future. During the follow-up, interviews in Romania included this topic of discussion, although we did not use the word "risk" in our conversations unless participants explicitly formulated it. In Catalonia, conversations about such risks arose in different moments despite researchers not necessarily including the issue on the agenda. 


\section{Results}

Results follow the structure of the research questions. The first one (RQ1) focuses on the empirical evidence gathered during the initial research period, while the second (RQ2) looks at the initial and the follow-up qualitative research.

\subsection{Older Individuals' Risk Perceptions and Media Discourses}

Between 2010 and 2012, concerns about different types of risks mostly arose spontaneously in conversations. About half of the Romanian participants brought up issues regarding health and mobile communication during the discussions. Some also discussed the risk of fraud or scams on mobile phones. Still, participants in Romania expressed low levels of concern. No one in Romania mentioned risks associated with antennas or the potential effects of electromagnetic fields. Conversely, in Catalonia, health risks, mostly connected to radiations, constituted the most significant concern, cited by almost four out of ten interviewed participants. Catalan participants expressed higher levels of concern than Romanian participants and focused their concerns more on health than on fraud and scams. This preliminary basic result suggested that an analysis of media content would be relevant, to search for differences in the prominent issues around mobile telephony.

The analysis focused on the total country corpus, not on specific media (see Figure 1). We took a grounded, quantitative approach to classify articles' dominant information. We identified five non-exclusive categories: (1) Daily life activities, which gathered news about general mobile phone services, health care and prevention information, protection and risk management, and a set of other everyday life issues; (2) Privacy, surveillance, and neutrality, which referred to news related either to legal or illegal activities in each of the three areas; (3) Health issues, which included news-positive, negative or neutral-about the direct impacts of mobile communication and two kinds of indirect impact: addiction and dependencies, and the environment and ecology. (4) The Other risks category included news on conflicts involving social norms - such as public exclusion and public blame; terrorist attacks; and road safety. Finally, (5) Scams and fraud referred to the news on these problems favored by the pervasiveness of mobile telephony.

News item content analysis showed rather different interests in the Romanian and Catalan media (Figure 1). We focused our interest on the three largest categories in each corpus and then on the largest subcategory of each one to identify the hot issues in each cultural context. In Romania, they are: first, Daily life activities (103 hits, 46\% of the corpus), with Protection and risk management (69 hits, $31 \%$ ) standing out as the most preeminent subcategory; second, Privacy, surveillance, and neutrality (87 hits, 39\%); third, Scams and fraud (83 hits, 37\%). In Catalonia, the first category is the same, Daily life activities (70 hits, $49 \%$ of the corpus), while the largest sub-category is Healthcare and prevention information (24 hits, 17\%). The second category is Health impact (59 hits, 41\%), with Negative effects (34 hits, 24\%) as the outstanding sub-category. Finally, the third category is Other risks (43 hits, 30\%).

We were able to identify three main trends. Firstly, Romanian's most prominent controversy in the media involved protection and risk management, whereas, in Catalonia, the media focused more on health issues and the direct negative impacts of mobile technology. Secondly, media discourse in Romania was rather nuanced regarding scams and fraud: from the use of mobile phones in academic dishonesty to commercial offers that had the specific purpose of scamming people. While this constituted the second most prominent category in the Romanian corpus, it was the least prominent in the Catalan corpus. Thirdly, illegal surveillance through mobile communication was a largely covered topic in the Romanian corpus, whereas in Catalonia this topic was rarely present. 

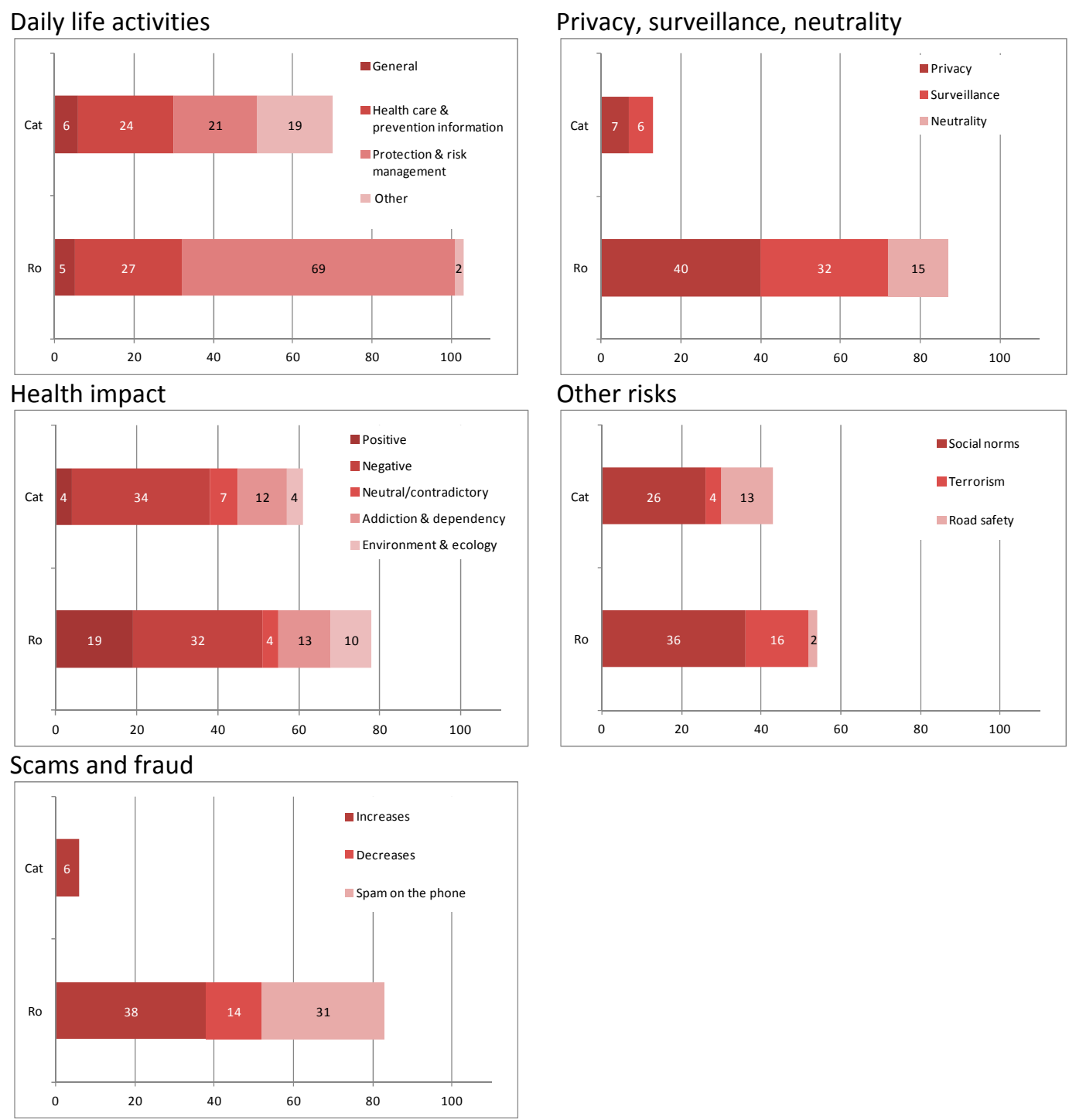

Figure 1. News by category, Romanian (Ro) and Catalan (Cat) corpus. Main categories are non-exclusive, sub-categories are exclusive. Romanian corpus: 224 news items; Catalan corpus: 144 news items.

Also, media discourse on the risks of mobile communication was different in the two countries in terms of source credibility and news category. In Catalonia, it mostly appeared in the Economics, International or Living in $B C N$ sections. In Romania, however, more than half of the articles appeared under the label useful things, grouped together with news about housing, diets or healthy living. Some dealt with unusual things (labeled as cool stuff to know), with most of the information coming from sources of differing credibility - several of them tabloids-published on the news portal.

Seniors' discourses were consistent with the media prominence of health and fraud risks in each country. In Romania, concern about health and mobile telephony expressed by older people was relatively low, although the topic appeared in over half of the interviews. Unlike older people from Catalonia, Romanian participants did not express concerns about electromagnetic radiations, and issues about them were hardly found in the Romanian media. Differences in seniors' discourses on health risks related to the way the media discussed them. In the Catalan media, articles on technology risks, such as radiation, tended to focus on individuals' responsibility. In the Romanian corpus, however, the focus was on everyday life and leisure activities. Few articles about mobile phone antennas and their potential risks appeared in the Romanian corpus, which is consistent with the 
fact that the topic never appeared in seniors' discourse. A similar consistency appears in the case of fraud risks. This category was more pervasive in Romania's media than Catalonia's, with Romanian participants reporting being more worried than those from Catalonia about the possibility of being scammed while using mobile phones. In contrast, surveillance and privacy issues did not appear in the Romanian seniors' discourse. A particular explanation for this discrepancy could be that, most of the time, media presented cases involving political or public figures in Romania; and participants-aware of this specific media content-might not have perceived themselves as vulnerable since they did not belong to the (political) elite of the country.

\subsection{Me Versus the Others: Risk Perception Can Depend on Who Faces the Risk}

Catalan participants had a more nuanced discourse on mobile communication-associated risks than their Romanian counterparts. We found three approaches in Catalonia during the whole period of observation: belief in adverse effects, skepticism, and belief in no "actual" negative consequences, all of which reflect "controversy". Arguments and described behaviors mostly referred to the assumed personal risk. A participant in the initial research in Barcelona even had a "protector stick" on her mobile handset to reduce radiations. She explained she had kept the piece stuck on the three mobile handsets she had purchased since her first one 12 years before the interview (Woman, 63). Aside from this particular case, strategies more commonly mentioned were: not wearing the phone too close to the body and leaving it outside the bedroom at night. Second, skeptical seniors claimed "nothing has been proven" and described opposing attitudes towards mobile communication: either they felt that it was not worth worrying about risks, or they took precautionary measures just in case.

I don't know if it's true or false. Me, until they prove the opposite, I feel it has no health disadvantages. (Woman, 96, Barcelona)

I never wear it on my body but always there, in the purse. Because (... ) I don't know to what extent radiations are good or bad, it hasn't been proven. (Woman, 66, Barcelona)

Finally, participants who considered adverse effects not to be "real" expressed their position. For instance, once asked, a participant stated that there were no disadvantages related to mobile telephony:

Not one. There're people who say that antennas affect health. There're people who oppose having an antenna on their roof. ( ... ) It's possible these antennas may have a [negative] influence, I don't know, I don't really believe it but it could be. (Man, 88, Barcelona)

Conversely, nobody from Romania mentioned risks associated with antennas or potential effects of electromagnetic fields in the different projects we conducted. Instead, Romanian participants mostly expressed concerns about fraud and scams. Some did not answer unknown numbers to avoid unwanted commercial calls. Others even reported behaving aggressively to such calls. Several participants reported acting in a precautionary way when strangers called:

I usually don't answer if I don't recognize the number. They [people with commercial offers] always call me. I learned to recognize them in a second and then I just hang up. I don't need them. (Man, 76, Bucharest)

Still, Romanian participants were concerned with health risks for younger family members(grand) children-or adolescents in general. They considered younger generations to be more exposed to radiation, permanently surrounded by electronic communication technologies they tended to overuse. Participants were not concerned with personal risks, as they believed they would appear after years of overuse. Yet they expressed concerns about the future of their children's health. In Catalonia, however, the discourse about health risks mainly focused on the risks for the self. A general idea, "this is not a problem for me," arose in both social contexts: 
Well, I don't know to what extent this kind of radiation can harm me for [being exposed] minutes. Also, as I don't usually wear [the mobile], I put it in my purse (... ) I don't think there is any effect. Maybe for those who spend twenty-four hours a day attached to the mobile phone, maybe there's [a negative effect]. (Woman, 60, Barcelona)

There're questions about the influence on our health. Specialists are going to research to see if there's any effect. I don't talk so much, but my daughter, she talks for hours [on the mobile] plus she uses a computer at work. I believe in time a person could be negatively influenced by this. (Woman, 63, Bucharest)

To sum up, participants perceived the risk associated with mobile communication as either a personal problem, as in Catalonia, or as an issue for others, as in Romania. In the former case, these others tended to be important, as they were close relatives. Still, some older participants did not show a high degree of concern and risks were attributed to others, namely younger generations, in the case of Romania.

\subsection{Perceived Risk and Uncertainty of Mobile Communication}

Both in the initial study and in the follow-up research, older people expressed concerns regarding risk and uncertainty around mobile communication. When talking about health issues, their perceptions mainly appeared to be shaped in terms of uncertainty, arguing that "nothing had yet been proven" and "more studies need to be done." As they did not necessarily detect a likelihood of damages to personal health in the foreseeable future-even less so regarding a technology for which there is no conclusive evidence-mobile communication and health risks referred to others in general and to younger generations in particular.

Who knows what will happen in the future? I will probably not live to tell, but I'm worried about all children, who spend hours on computers and telephones; and in which way this will affect their health. New types of diseases will come from the use of all these [technologies]. (Woman, 65, Bucharest)

Also, concerns regarding the negative influence of mobile communication on health were described as "uncontrollable" and not related to personal decisions. This idea particularly arose among Romanian participants, linked to lower trust in authorities and State institutions. In this sense, participants expressed concerns about the credibility of information received from the authorities regarding communication technologies and health risks.

I have read something in a newspaper about radiations caused by the mobile phone. It was not clear to me and I am wondering if they are telling the truth. I mean, they are interested in selling the products, right? Then, you see [ . . . I in Romania, they [authorities] never do the right thing when people's lives are in danger. (Man, 67, Bucharest)

Other concerns about the use of mobile telephony, such as scams and fraud, were described by participants more as risks than uncertainty. The knowledge about the likelihood of scam situations came directly from the media and matched their direct or indirect experiences.

I took the [prepaid] card; I put it in the telephone on Friday and Monday I had nothing. They'd stolen my money. When I called them [the company], they said I had used it [my airtime], but it wasn't true. Dominica [a friend] called them and made a scandal because this had also happened to her twice. But I think it was Adela [the post office attendant who actually inserted the card in the phone] who took them. (Woman, 70, rural Romania)

I have seen on TV that they would call you and ask for information about your bank account or they would say that your son had an accident and then by the time you came to your senses, the money was gone. I know they target old people; I mean nobody tried this with me, but I know somebody who was left without savings. (Man, 63, Bucharest) 
The more technologically skilled participants expressed concerns about the use of different communication technologies regarding predictability. They were aware that digital communication is changing fast and they have limited capabilities to predict the number of risks technology will bring in the future. As a result, sometimes they were more reluctant in adopting new communication technology and skeptical about using them. In Romania, such participants were mostly men with a technical background, coming from urban areas. They were struggling between their skepticism and the social pressure to use the latest technologies.

I would like to learn more about the use of Facebook. I have an account, but I don't use it. I've been an engineer for 30 years, and I know how easily somebody can access your account when you use certain applications. So, I am more interested in finding out more about security issues when using Facebook. Well, I have to admit that my wife convinced me to come to this workshop. (Man, 65, Bucharest)

In Barcelona, at the end of the period, some participants expressed having to cope with the risks new digital features bring with them, such as permanent surveillance from digital companies or public administration. For instance, a participant agreed with the idea that "Google knows everything" about us but "if you want to be in [this is the price]" (Woman, 65, Barcelona). Another participant justified her lack of concern by stating that she is "an average person [ ... ] not interesting at all" (Woman, 71, Barcelona). In this case, risk perception is minimized, as the person does not stand out and would not draw specific interest from those who might be gathering her digital data.

It is worth mentioning that, both in Romania and Catalonia, the negative aspects of using mobile communication tended to diminish, while a generally optimistic view of the role of technologies in people's lives tended to increase. Particularly in Romania, focus group participants who expressed negative views about mobile communication were inhibited by the majority-who had a techno-optimistic view. During personal interviews, people were less susceptible to social pressure and expressed more concerns, all the while maintaining a generally positive view towards the use of mobile technology. Participants' associations between communication technology and general development/progress are salient in Romanian participants' discourse. People not only reported social pressure to adopt different devices or applications, but they also described technological skills as a type of progressive behavior.

We have to learn if we don't want to be left behind ... I have three tablets, and in the beginning, I thought I would never learn to use a tablet. I thought I was not capable enough. People like me think like this, and I would like to tell them that nothing is that difficult and they have to try because this is the direction in which society is moving. (Woman, 63, Bucharest)

Association of digital skills with (personal) progress appeared both in Romania and in Catalonia. However, some of the Romanian participants felt hopeless. Not having enough skills, they struggled not to be excluded. Although we did not find risk of social exclusion in the media content analysis or explicitly in people's discourse, participants implicitly referred to a feeling of "being left behind." In fact, the tendency of Romanian participants to talk merely about the positive outcomes of mobile communication, giving less importance to negative concerns compared to those from Catalonia, could also be interpreted by their view of technology in relation to progress.

\section{Discussion}

In the following section we will discuss the main findings of the research conducted in the two countries and then analyze the implications of such findings, expressing visions of aging futures in societies with different perceptions of risks.

First, our research reveals that seniors' discourses are consistent with different types of risks' media prominence in each country: media discourse in Romania focused on scams and fraud, which was consistent with older people's discourse, whereas in Catalonia, the media focused more on health issues, 
as did participant concerns expressed in the interviews. Differences in seniors' discourses on health risks relate to the way the media discussed them, with Romanian participants expressing no concerns about electromagnetic radiations, unlike Catalan participants. The literature on risk perception draws the attention to the fact that the media is a key player in raising public concerns [18,34], but studies in which people's perceptions are combined with media reflections are scarce, so there is little evidence about the correspondence between media content and risk and uncertainty for lay people. Also, it might be that, in the case of risk associated with digital communication, media reflection plays a more important role because audiences are facing information about precautionary actions, with media content increasing the uncertainty (risk not yet proven) rather than presenting risks (defined by the likelihood of adverse consequences occurring). Particularly in the case of health concerns and mobile telephony, the presence of precautionary information in the media would probably create greater risk perception among the audience [37]. This could explain why we found a correspondence between media content and people's concerns in Catalonia, particularly in this category (Health risks). Another potential explanation could be that Health risks are more salient to older people in general; any time this category appears in the media, it will raise awareness particularly among older audiences. Unfortunately, as far as we know, no study researches what happens with precautionary information presented in the media in response to older audiences. In the case of the Scams and fraud category, mostly present in the Romanian media and in Romanian participants' discourses, the relation between media content and people's perception might follow a different route: the media presents differently the likelihood of being a victim of scams and fraud, with higher risks for less technology-savvy individuals. It could be that such information was more salient for Romanian seniors, taking into account the differences in mobile technology adoption by older people in the two countries [44]. We looked for a correspondence between public agenda and media agenda in seniors' discourses in the two social contexts, and no causality is claimed in the current work. Although media content might have influenced people's risk perceptions, it would be difficult to infer any causal direction based on our methodology and findings.

Second, risk evaluation in the two social contexts was different, with Romanian seniors being more concerned with risk pertaining to other people, namely health risks for younger family members, whereas seniors from Catalonia were more concerned with risk pertaining to them. The literature [25] presents risk for family members as a particular type of risk perception with an expected higher degree of worry; this is consistent with what we found in our Romanian sample. Still we lack cross-cultural studies to explore further why we did not find similar results in Catalonia. One potential explanation rests in the differences in media content between the two social contexts, with references to health risk being prominent in the Catalan media and practically absent in the Romanian media. It might be that people are more concerned by risks that pertain to them when those risks are salient in the public discourse and that they concern themselves more with general risk, risk pertaining to other people, when the information is scarce. Also, we can argue that when older people evaluate the risks of mobile technology use for younger family members, they are basing their information on the frequency with which they interact with their children and grandchildren. We know, for example, from surveys conducted in some European countries [54] that approximately $17 \%$ percent of grandparents in Spain help daily in looking after their grandchildren, and this pattern in higher in Southern European countries than Nordic countries, where most grandparents provide "some help", but not on a daily basis. Although these studies on grandparenting do not include Eastern European countries or developing countries in general, the same report [51] (p. 3) argued that in Spain, Portugal, Italy and Romania, grandparents provide more intensive care for their grandchildren than in other countries in Europe, due to the lack of the opportunities for mothers to work part-time. Still, of the four countries listed, the percentage of grandparents who provide intensive care for their grandchildren without the presence of parents is highest in Romania. Consequently, our results could actually reflect the differences between Romania and Catalonia in the way older people look after younger family members. Further investigation is necessary to explain these findings. 
Third, people's concerns about health risk and mobile communication were shaped in uncertainty terms ("nothing had yet been proven") and as an uncontrollable type of risk. The "uncontrollability" or risk associated with mobile telephony was more salient in the case of Romanian seniors, who also expressed distrust in information offered by authorities. Other concerns about the use of mobile telephony, such as scams and fraud, were described by participants more in terms of risks (knowledge about likelihood) than uncertainty. Also, participants from both countries were concerned about their abilities to keep up with the rapid change in communication technology and reported social pressure to cope with the continuous changes. We started this paper by saying that risks associated with mobile telephony are more linked with uncertainty because people cannot evaluate accurately the outcome. Regardless, our data shows that for some types of risk, such as fraud and scams, people were able to form accurate predictions, with information mainly taken from the media. Furthermore, it is not only the trust in a particular source providing information about risks but also the (dis)trust in authorities in general that shapes people's risk perceptions. In this respect, the differences found between the two social contexts could reflect differences not only in media content but also in the level of institutional trust.

Our findings suggest that older people worry about their ability to stay up-to-date with the latest technologies. This result could also be found in other age groups. Still, our participants described having technological skills as a type of progressive behavior and tended to play down the negative aspects of mobile communication use in favor of a generally techno-optimistic view of digital technologies' role in everyday life. Such association between technology use and personal progress could be particularly prevalent in a senior group, as they are the ones who face the most social pressure with regard to technology adoption.

Fourth, seniors from Romania included in their discourses about communication technologies references to the country's progress/development more than those from Catalonia. This is consistent with what we found in studies on other developing countries [19,45], in which the benefits of technology were taken for granted. In addition to social pressure, such results explain why we found a generally positive view of mobile communication use in everyday life in the interviews conducted in Romania and reluctance to express strong negative opinions.

We can argue that in developing countries there is a center-periphery discourse on communication technology - largely accepted as a sign of progress-where people are still concerned about different risks but media discourse is rather weak, more so than in developed countries-where there are deeper media debates about electromagnetic fields, radiations and impact on community life. In countries where technology is perceived as good per se, the techno-optimistic discourse is reinforced not only by media content but also by the groups exposed to the highest social pressure towards technology adoption [19]—for example, seniors.

\section{Conclusions and Implications for Future Research}

We used as a starting point the debate over the emergent risks [3,4] in current society, arguing that wireless communication technology constitutes one of the new kinds of risks that are "all around" and become more present both in people's perceptions and media reflections on society. Also, it is interesting to ponder how future societies will shape the perception of risk related to mobile communication and change the level of precaution due to the demographic shift towards aging. As older people tend to be more concerned about risks than younger generations and also approach mobile communication in a utilitarian way-for example, searching for safety and security benefits-this paper contributes to furthering the discussion on aging futures and wireless communication risks by looking both at older people's risk perception and media discourses.

We found that seniors' discourses were consistent with media prominence of different types of risks in each country. Still, the correspondence between media content and people's concerns in Catalonia was mainly in the Health risks category, whereas in Romania it was in the Scams and fraud category. We believe that this is a reflection of the differences in the mobile technology perceptions of 
older people in developing and developed countries (RQ1). Such an interpretation is supported by the fact that seniors from Romania, more so than those from Catalonia, included in their discourses references to the country's progress/development. Also, evaluation of risk in the two social contexts was different, with Romanian seniors being more concerned about risk as it pertained to others, whereas seniors from Catalonia were more concerned with risks that pertained to them (RQ2). These findings are particularly of interest and require further research.

The data gathered in the two countries (Romania and Catalonia, Spain) by means of semi-structured interviews and content analysis allow us to discuss how risk perception regarding wireless technologies is shaped in different social contexts. Perceptions in relation to mobile communication technologies are different in the two countries, as the data from the opinion polls revealed, with the Romanian population expressing lower levels of concern than that of Spain. Therefore, we expected older people's discourses to be different when talking about mobile communication as well as the prominence given the types of risks by the media in the two countries.

Our findings open the debate about visions of aging futures in societies with different perceptions of risks. There is no doubt that the pervasiveness of wireless communications defines modern risk societies, shaping the way we age. However, as media content presents differently the risks associated with digital technologies in different countries and indicates some risks as being more salient than others, people's perceptions would be formed accordingly. We might find that older people are paying more attention to health risks and mobile communication than other age categories, but not necessarily in the countries where media discourse on such issues is weak. Instead of being concerned with the risk of technology use that pertains to them, people of a certain age feel that they are not necessarily at risk and worry about younger family members. Such a tendency could be stronger in countries in which older people are more involved in looking after the children and grandchildren. Also, as technology products are taken less and less for granted, people will start being less techno-optimistic and express their technology use concerns. Still, older people probably face greater social pressure to adopt the latest communication technology than other age groups, and, consequently, they might end up having a more optimistic discourse about the role of technology in everyday life. Our data suggest ways of continuing the current research by analyzing the role of family interactions in older people's discourses on technology risks and also the convergence between media content and the risk perceptions of people from different audiences.

\section{Limitations and Future Work}

The empirical data that support our analysis face some limitations. First, public perception of the risks associated with mobile communication might have changed during the 7-year period (2010-2016) analyzed. We can assume that the number of mobile phone users was already stable during the period since mobile penetration rates were over $100 \%$ in both Romania and Spain by 2010 [55]. Similarly, and despite the fast-changing digital landscape, opinions and risk perceptions would have stabilized as well, as shown by the lack of opinion polls we already mentioned. However, further empirical research could confirm this assumption, most likely by means of a representative survey with an appropriate representation of older age groups. In parallel, an enlarged press content analysis would also help in better understanding the evolution of the public discourse.

New empirical research should also address the differences between the rural and urban contexts. While in Romania we interviewed older individuals living in both urban and rural contexts, in the Catalan case, interviews concentrated in the Barcelona metropolitan area. Risk perceptions associated with mobile telephony might change between urban and rural areas, as when it comes to analyzing the perceived relationship of mobile communication and risk. Therefore, a possible development could be to rely on Bourdieu's concept of habitus [56] to explore further the perceived relationship of mobile communication and risk, and the visions of aging futures held by different social groups. 
Acknowledgments: We thank the participants for their generosity. The work of the first author was supported by the UEFISCDI, under Grant PN-II-RU-TE-2014-4-0429. The paper benefited from ACM Research Network and ACT Project funding (SSHRC refs. 890-2010-0138, 895-2013-1018). Daniel Blanche helped in statistical data gathering.

Author Contributions: The first author, Loredana Ivan, led or directly participated in the qualitative research and content analysis conducted in Romania. The same applies to the second author, Mireia Fernández-Ardèvol, in Catalonia.

Conflicts of Interest: The authors declare no conflict of interest. The funding sponsors had no role in the design of the study; in the collection, analyses, or interpretation of data; in the writing of the manuscript; or in the decision to publish the results.

\section{References}

1. Cimperman, M.; Brenčič, M.M.; Trkman, P.; Stanonik, M.L. Older adults' perceptions of home telehealth services. Telemed. E-Health 2013, 19, 786-790. [CrossRef] [PubMed]

2. Schulz, R.; Wahl, H.-W.; Matthews, J.T.; De Vito Dabbs, A.; Beach, S.R.; Czaja, S.J. Advancing the aging and technology agenda in gerontology. Gerontologist 2015, 55, 724-734. [CrossRef] [PubMed]

3. Beck, U. Risk Society: Towards a New Modernity; Theory, Culture \& Society; SAGE: London, UK, 1992.

4. Giddens, A. The Consequences of Modernity; Polity Press: Cambridge, UK, 1990.

5. Olofsson, A.; Öhman, S. Views of risk in Sweden: Global fatalism and local control—An empirical investigation of Ulrich Beck's theory of new risks. J. Risk Res. 2007, 10, 177-196. [CrossRef]

6. Gupta, N.; Fischer, A.R.H.; Frewer, L.J. Socio-psychological determinants of public acceptance of technologies: A review. Public Underst. Sci. 2012, 21, 782-795. [CrossRef] [PubMed]

7. Fischhoff, B.; Kadvany, J.D. Risk: A Very Short Introduction; Very short introductions; Oxford University Press: Oxford, NY, USA, 2011.

8. Flynn, R. Risk and the public acceptance of new technologies. In Risk and the Public Acceptance of New Technologies; Flynn, R., Bellaby, P., Eds.; Palgrave Macmillan: Hampshire, UK, 2007; pp. 1-23.

9. Donkers, B.; Melenberg, B.; Van Soest, A. Estimating risk attitudes using lotteries: A large sample approach. J. Risk Uncertain. 2001, 22, 165-195. [CrossRef]

10. TNS Opinion \& Social Electromagnetic Fields. Special Eurobarometer 347/Wave 73.3; European Commission, Directorate General for Health and Consumer Affairs: Brussels, Belgium, 2010.

11. Fischer, A.R.H.; Frewer, L.J. Public acceptance of new technologies in food products and production. In Risk and the Public Acceptance of New Technologies; Flynn, R., Bellaby, P., Eds.; Palgrave Macmillan: Hampshire, UK, 2007; pp. 66-85.

12. Wong, C.Y. Exploring the relationship between mobile phone and senior citizens: A Malaysian perspective. Chui Yin Wong Int. J. Hum. Comput. Interact. 2011, 2, 65-77.

13. Eurostat Individuals-devices used to access the internet [isoc_ci_dev_i] 2016. Available online: http://ec. europa.eu/eurostat/web/digital-economy-and-society/data/database (accessed on 2 February 2017).

14. Kurniawan, S. Older people and mobile phones: A multi-method investigation. Int. J. Hum. Comput. Stud. 2008, 66, 889-901. [CrossRef]

15. Dolan, M.; Rowley, J. The precautionary principle in the context of mobile phone and base station radiofrequency exposures. Environ. Health Perspect. 2009, 117, 1329-1332. [CrossRef] [PubMed]

16. Stilgoe, J. The (co-)production of public uncertainty: UK scientific advice on mobile phone health risks. Public Underst. Sci. 2007, 16, 45-61. [CrossRef] [PubMed]

17. Castells, M.; Fernández Ardèvol, M.; Qiu, J.L.; Sey, A. Mobile Communication and Society: A Global Perspective; MIT: Cambridge, MA, USA, 2006.

18. Barnett, J.; Timotijevic, L. Making sense of uncertainty and precaution: The example of mobile telecommunications. In Risk and the Public Acceptance of New Technologies; Flynn, R., Bellaby, P., Eds.; Palgrave Macmillan: Hampshire, UK, 2007; pp. 86-106.

19. Van Kleef, E.; Fischer, A.R.H.; Khan, M.; Frewer, L.J. Risk and benefit perceptions of mobile phone and base station technology in Bangladesh. Risk Anal. 2010, 30, 1002-1015. [CrossRef] [PubMed]

20. Van Loon, J. Virtual risks in an age of cybernetic reproduction. In The Risk Society and Beyond: Critical Issues for Social Theory; Adam, B., Beck, U., Van Loon, J., Eds.; SAGE: London, UK, 2000; pp. 165-183. 
21. SCENIHR Opinion on potential health effects of exposure to electromagnetic fields (EMF). Scientific Committee on Emerging and Newly Identified Health Risks SCENIHR; European Union: Brussels, Belgium, 2015; p. 288.

22. Siegrist, M.; Keller, C.; Cousin, M.-E. Implicit attitudes toward nuclear power and mobile phone base stations: Support for the affect heuristic. Risk Anal. 2006, 26, 1021-1029. [CrossRef] [PubMed]

23. Sjöberg, L. The different dynamics of personal and general risk. Risk Manag. 2003, 5, 19-34. [CrossRef]

24. Sjöberg, L. Factors in risk perception. Risk Anal. 2000, 20, 1-12. [CrossRef] [PubMed]

25. Sjöberg, L. Worry and risk perception. Risk Anal. 1998, 18, 85-93. [CrossRef] [PubMed]

26. Mohun, A. Risk: Negotiating Safety in American Society; Johns Hopkins University Press: Baltimore, MD, USA, 2013.

27. Boyne, R. Risk; Concepts in the social sciences; Open University: Buckingham, UK, 2003.

28. Douglas, M.; Wildavsky, A.B. Risk and Culture: An Essay on the Selection of Technological and Environmental Dangers; University of California Press: Berkeley, CA, USA, 1982.

29. Jackson, J.; Allum, N.; Gaskell, G. Bridging levels of analysis in risk perception research: The case of the fear of crime. Forum Qual. Sozialforschung/Forum: Qual. Soc. Res. 2006, 7, 20.

30. Eldridge, J.; Reilly, J. Risk and relativity: BSE and the British media. In The Social Amplification of Risk; Pidgeon, N.F., Kasperson, R.E., Slovic, P., Eds.; Cambridge University Press: Cambridge, UK, 2003; pp. 138-155.

31. Slovic, P. Informing and educating the public about risk. In The Perception of Risk; Slovic, P., Ed.; Earthscan: London, UK, 2000; pp. 182-198.

32. Burgess, A. Cellular Phones, Public Fears, and a Culture of Precaution; Cambridge University Press: New York, NY, USA, 2004.

33. Drake, F. Mobile phone masts: Protesting the scientific evidence. Public Underst. Sci. 2006, 15, 387-410. [CrossRef]

34. Elvers, H.-D.; Jandrig, B.; Grummich, K.; Tannert, C. Mobile phones and health: Media coverage study of German newspapers on possible adverse health effects of mobile phone use. Health Risk Soc. 2009, 11, 165-179. [CrossRef]

35. Claassen, L.; Bostrom, A.; Timmermans, D.R.M. Focal points for improving communications about electromagnetic fields and health: A mental models approach. J. Risk Res. 2016, 19, 246-269. [CrossRef]

36. Cousin, M.; Siegrist, M. Risk perception of mobile communication: A mental models approach. J. Risk Res. 2010, 13, 599-620. [CrossRef]

37. Barnett, J.; Timotijevic, L.; Vassallo, M.; Shepherd, R. Precautionary advice about mobile phones: Public understandings and intended responses. J. Risk Res. 2008, 11, 525-540. [CrossRef]

38. Wiedemann, P.M.; Schuetz, H.; Boerner, F.; Clauberg, M.; Croft, R.; Shukla, R.; Kikkawa, T.; Kemp, R.; Gutteling, J.M.; de Villiers, B.; et al. When precaution creates misunderstandings: The unintended effects of precautionary information on perceived risks, the EMF case: When precaution creates misunderstandings. Risk Anal. 2013, 33, 1788-1801. [CrossRef] [PubMed]

39. Timotijevic, L.; Barnett, J. Managing the possible health risks of mobile telecommunications: Public understandings of precautionary action and advice. Health Risk Soc. 2006, 8, 143-164. [CrossRef]

40. Freudenstein, F.; Wiedemann, P.M.; Varsier, N. Exposure knowledge and risk perception of RF EMF. Front. Public Health 2015, 2, 289. [CrossRef] [PubMed]

41. Kowall, B.; Breckenkamp, J.; Blettner, M.; Schlehofer, B.; Schüz, J.; Berg-Beckhoff, G. Determinants and stability over time of perception of health risks related to mobile phone base stations. Int. J. Public Health 2012, 57, 735-743. [CrossRef] [PubMed]

42. Curseu, D.; Popa, M.; Sirbu, D. The Romanian public's perception of electromagnetic fields risk. In International Conference on Advancements of Medicine and Health Care through Technology; Vlad, S., Ciupa, R.V., Eds.; Springer: Berlin/Heidelberg, Germany, 2011; Volume 36, pp. 320-323.

43. Espluga, J. Precautionary local politics and coping with risks of radiofrequency fields in Spain. Int. J. Global Environ. Issues 2005, 5, 68. [CrossRef]

44. Fernández-Ardèvol, M.; Ivan, L. Older people and mobile communication in two European contexts. Rom. J. Commun. Public Relat. 2013, 15, 83-98. [CrossRef]

45. Renn, O.; Benighaus, C. Perception of technological risk: Insights from research and lessons for risk communication and management. J. Risk Res. 2013, 16, 293-313. [CrossRef] 
46. Maxwell, J.A. Qualitative Research Design: An Interactive Approach. In Applied Social Research Methods, 2nd ed.; SAGE: Thousand Oaks, CA, USA, 2005; Volume 41.

47. BRAT Romanian Bureau of Audit for Reach Audit tiraje: Cifre de difuzare. Available online: http://www. brat.ro/audit-tiraje/cifre-de-difuzare (accessed on 1 October 2010).

48. Fundació audiències de la comunicació i la cultura (FUNDACC). Resum 3a onada 2012: Baròmetre de la comunicació i la cultura, Catalunya-REO 706; FUNDACC: Barcelona, Spain, 2012. Available online: www. fundacc.org (accessed on 13 April 2017).

49. Morse, J.M.; Barrett, M.; Mayan, M.; Olson, K.; Spiers, J. Verification strategies for establishing reliability and validity in qualitative research. Int. J. Qual. Methods 2002, 1, 13-22. [CrossRef]

50. Ivan, L.; Hebblethwaite, S. Grannies on the net: Grandmothers' experiences of Facebook in family communication. Rom. J. Commun. Public Relat. 2016, 18, 11. [CrossRef]

51. Ivan, L.; Dumitriu, D.-L.; Savuelscu, R. Older people in digital creation contexts: Building a participatory action research design. In Proceedings of the 9th International Conference for Entrepreneurship, Innovation and Regional Development; Zbuchea, A., Nikolaidis, D., Eds.; Comunicare.ro: Bucharest, Romania, 2016; pp. 52-63.

52. Rosales, A.; Fernández-Ardèvol, M. Beyond WhatsApp: Older people and smartphones. Rom. J. Commun. Public Relat. 2016, 18, 27-47. [CrossRef]

53. Fernández-Ardèvol, M.; Rosales, A. My interests, my activities: Learning from an intergenerational comparison of smartwatch use. In Human-Computer Interaction International; Zhou, J., Salvendy, G., Eds.; Springer: Basel, Switzerland, in press.

54. Glaser, K.; Price, D.; Di Gessa, G.; Ribe, E.; Stuchbury, R.; Tinker, A. Grandparenting in Europe: Family Policy and Grandparents' Role in Providing Childcare; Grandparents Plus: London, UK, 2013.

55. ITU Time series by country (until 2015): Mobile-cellular subscriptions. Excel file. Available online: http: //www.itu.int/en/ITU-D/Statistics/Pages/stat/default.aspx (accessed on 1 February 2017).

56. Bourdieu, P. Outline of a Theory of Practice; Cambridge University Press: Cambridge, UK, 1977.

(C) 2017 by the authors. Licensee MDPI, Basel, Switzerland. This article is an open access article distributed under the terms and conditions of the Creative Commons Attribution (CC BY) license (http:/ / creativecommons.org/licenses/by/4.0/). 